Frühe deutsche Kinematographie 
Corinna Müller

\section{Frühe deutsche Kinematographie}

Formale, wirtschaftliche und kulturelle Entwicklungen 1907 - 1912

Verlag J.B. Metzler Stuttgart · Weimar 
Die Deutsche Bibliothek - CIP-Einheitsaufnahme

Müller, Corinna:

Frühe deutsche Kinematographie : formale, wirtschaftliche und kulturelle Entwicklungen 1907-1912 / Corinna Müller. -

Stuttgart; Weimar : Metzler, 1994

ISBN 978-3-476-01256-2

ISBN 978-3-476-01256-2

ISBN 978-3-476-03560-8 (eBook)

DOI 10.1007/978-3-476-03560-8

Dieses Werk einschließlich aller seiner Teile ist urheberrechtlich geschützt.

Jede Verwertung außerhalb der engen Grenzen des Urheberrechtsgesetzes ist ohne Zustimmung des Verlages unzulässig und strafbar. Das gilt insbesondere für Vervielfältigungen, Übersetzungen, Mikroverfilmungen und die Einspeicherung und Verarbeitung in elektronischen Systemen.

(C) 1994 Springer-Verlag GmbH Deutschland

Ursprünglich erschienen bei J.B. Metzlersche Verlagsbuchhandlung und Carl Ernst Poeschel Verlag GmbHin Stuttgart 1994 


\section{Inhalt}

Einleitung

\section{Teil I: Kurzfilmzeit}

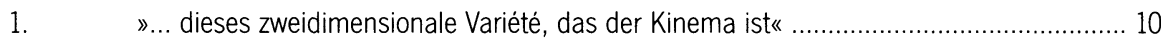

1.1. Die Verwurzelung der deutschen Kinematographie im Varieté ...................................... 11

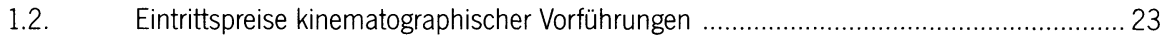

2. Kinogründungskonjunktur und deren Auswirkungen .............................................. 29

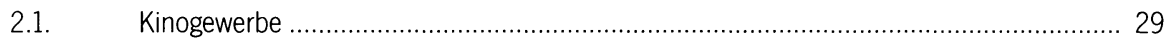

2.1.1. Vom ১Ladenkino zum `Kino-Palast _........................................................................ 29

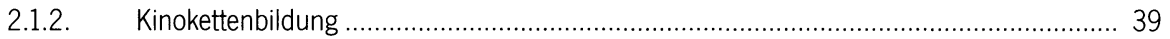

2.1.3. Programmgestaltung als Mittel des Wettbewerbs ....................................................... 43

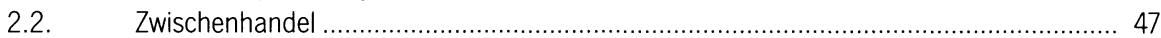

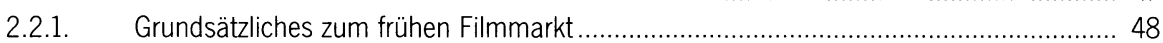

2.2.2. Kommerzielles Verleihwesen .............................................................................. 49

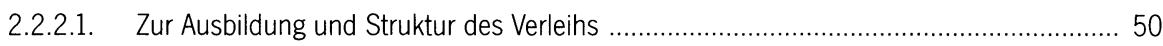

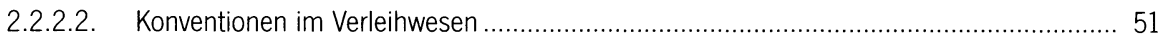

2.2.2.3. Systemschwächen im kommerziellen Verleihwesen .................................................... 53

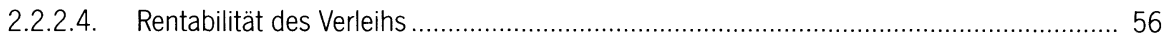

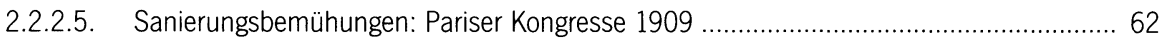

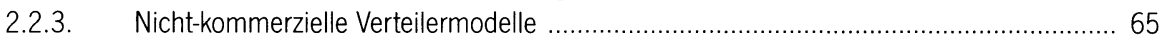

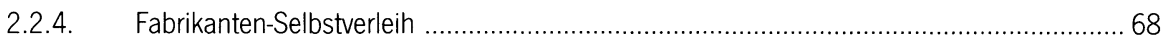

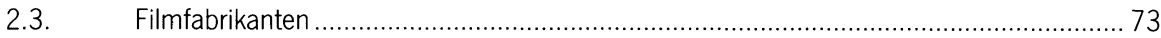

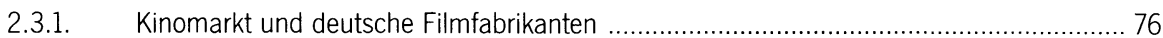

2.3.1.1. Eingangsvoraussetzungen deutscher Fabrikanten zur Filmherstellung ............................ 77

2.3.1.2. Tonbild-Kinematographie als Schwerpunkt deutscher Fabrikation ................................... 79

2.3.1.3. Vom Tonbild zum stummen Spielfilm: Umorientierung Messters auf den Kinomarkt ....... 83

2.3.1.4. Zu Produktions- und Absatzlage und Maßnahmen zur Absatzsteigerung ......................... 84

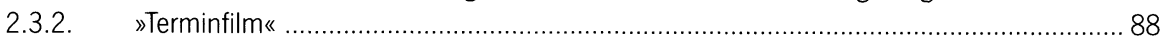

2.3.3. Wettbewerbsziel in der frühen Filmherstellung .......................................................... 94

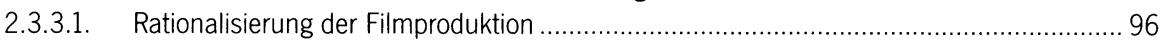

2.3.4. Möglichkeiten deutscher Filmhersteller zur Verbesserung ihrer wirtschaftlichen Lage ...... 99

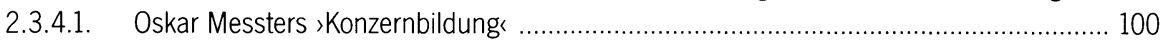

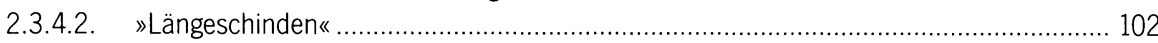

\section{Teil II: IDurchbruch und Etablierung des langen Spielfilms}

3. Strukturwandel im Verleihwesen: Verleih einzelner Filme ............................................ 105

3.1. Grundzüge bei der Herausbildung eines Verleihangebots einzelner Filme zwischen 1907 und 1909/10 ......................................................... 105

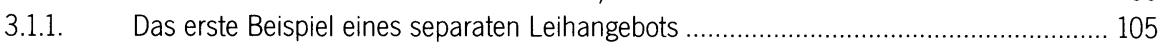

3.1.2. Nachfragesituation auf dem deutschen Filmmarkt .................................................. 108 
3.1.3. Institutionalisierung des separaten Verleihs einzelner Filme .................................... 110

3.2. Entwicklung auf dem deutschen Filmmarkt zwischen September 1910 und April 1911 .. 112

Exkurs: Dänische Langfilm-Produktion ................................................................. 124

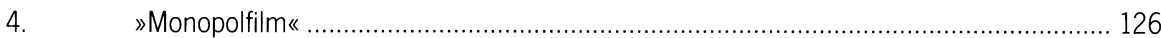

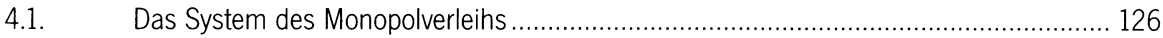

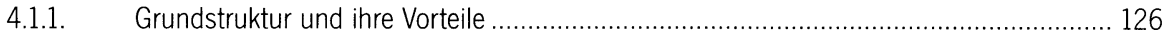

4.1.2. Marktstrukturierung mittels des Monopolverleihs .................................................. 128

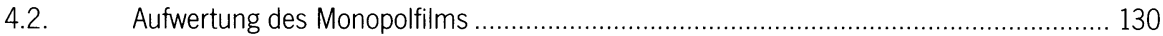

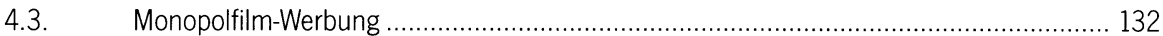

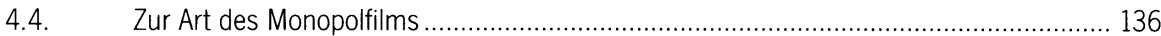

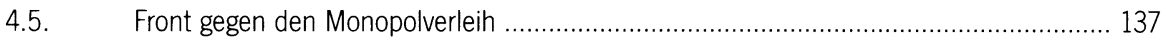

4.6. Gefährdung des Monopolverleihs durch lange Terminfilme .......................................... 140

4.7. Etablierung des Monopolverleihs mit Hilfe des Stars .................................................. 143

4.7.1. Das erste Beispiel des Stareinsatzes durch den Monopolverleih 1911: »Asta Nielsen« .. 144

4.7.2. Basis der Monopolfilm-Starserie: Der langfristige

Monopolvertrag auf die Präsentation des Stars ........................................................ 153

4.7.3. Leihkonditionen der ersten Monopol-Starfilme ........................................................... 156

4.7.4. Begünstigende Faktoren für den Erfolg der Monopolfilm-Starserie .............................. 157

5. Auswirkungen des langen Films für die Sparten der Filmwirtschaft ............................ 159

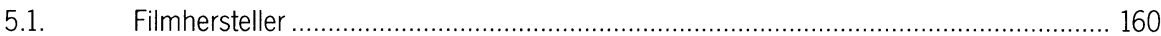

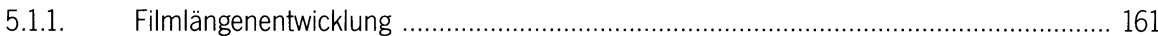

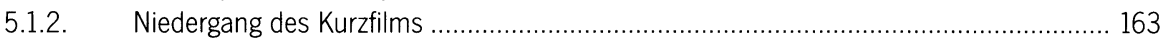

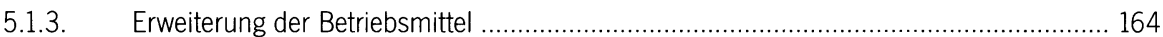

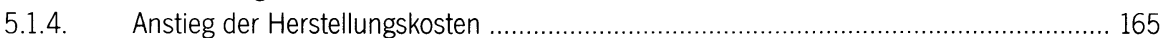

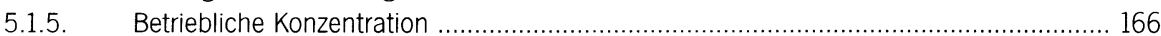

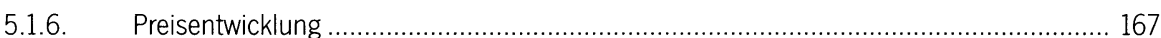

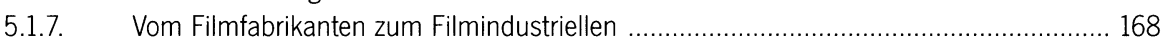

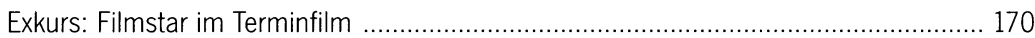

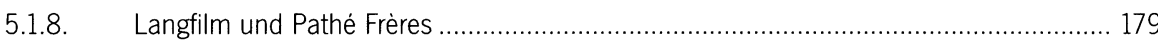

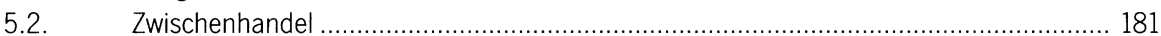

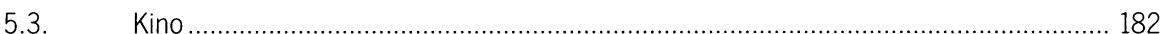

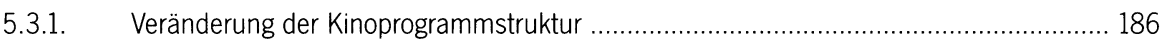

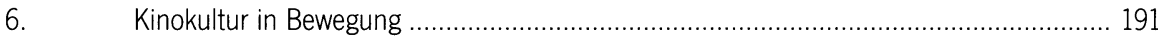

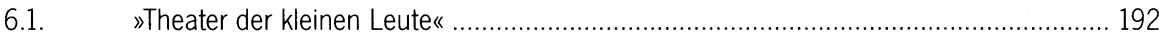

6.2. »Theater des Volkes« - Kino und Bildungskultur ............................................................ 200

6.3. Formkultur: Mit dem Dauerfilm aufs Niveau ............................................................ 209

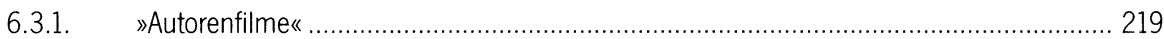

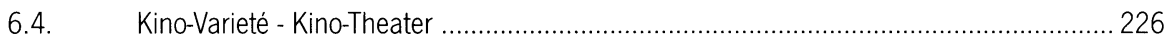

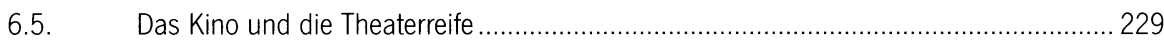

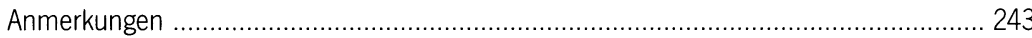

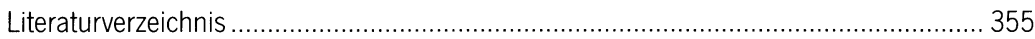

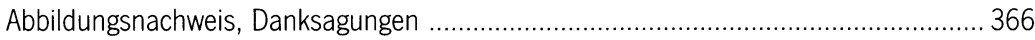

